\title{
Research on the Evaluation of Reading Promotion in University Libraries*
}

\author{
Ying Zeng \\ Library \\ China West Normal University \\ Nanchong, China
}

\author{
Yuanhua Chen \\ Personnel Office \\ China West Normal University \\ Nanchong, China
}

\begin{abstract}
The implementation of reading promotion evaluation under the new media environment can promote the sustainable development of reading promotion in university libraries, promote the effective development of reading promotion activities, and promote the sound business service institutions of university libraries. The evaluation of reading promotion needs to adhere to the principles of being peopleoriented and operable and combining qualitative and quantitative analyses. In the evaluation construction, people should establish the evaluation system, and pay attention to the development of evaluation implementation and evaluation feedback
\end{abstract}

Keywords-new media environment; university library; reading promotion work; evaluation

\section{INTRODUCTION}

At present, reading promotion has become the focus of most public libraries and university libraries. Some libraries not only have made a lot of useful exploration in practice, but also have a heated discussion on the evolution, mode, current situation and countermeasures of reading promotion, which brings together fresh experience and typical cases. Under the new media environment, the work of reading promotion in university libraries has various forms and various categories, but its effect needs to be evaluated to promote the effective development of reading promotion in university libraries [Yan, 2018]. Through the support of government legislation or fund associations, North American countries investigate and evaluate the library promotion and national reading status, so as to continuously improve the reading efficiency and national literacy. In contrast, under the new media environment, China's reading promotion work and reading activities are still relatively imperfect, the coverage of activities is narrow, the system is insufficient, the activities are mere formality, and the evaluation of reading activities and reading promotion work is relatively lagging behind. Most of the reading promotion activities have not been evaluated after the end of the activities, which leads to the failure to evaluate the effectiveness of the

*Fund: Supported by the Meritocracy Research Funds of China West Normal University "Study on the Reading Promotion Service of University Library in the Full Media Era" (17YC413), one of the achievements of the 2018 project "Reading Research of Family Library Branch Under the Strategy of Rural Revitalization" in the 13th Five-Year Plan of Social Science Research of Nanchong City (NC2018B103). activities and to make an effective summary of the whole process of the activities. As a result, there will be a lack of in-depth understanding of the activities, failing to leave valuable experience and lessons for the next activities and in the mode and side of the activities, law and content cannot be very innovative. Effective evaluation of reading promotion can not only improve the quality of college students' training, but also affect the level of library's reading service and service level. The evaluation of reading promotion and reading promotion should be as important as reading promotion and activity itself, and the establishment of evaluation mechanism should be the focus. Therefore, it is of practical significance to explore effective evaluation of reading promotion.

\section{IMPORTANCE OF READING PROMOTION WORK EVALUATION}

\section{A. Promoting the Sustainable Development of Reading Promotion}

In the information society, the reading behavior and reading ability of the citizens reflect the cultural soft power of the country and the reading literacy of the whole nation. All relevant cultural departments and university libraries in China actively carry out reading promotion activities, which can not only improve the utilization rate of books in libraries, but also actively guide readers to form the concept of reading. Although this is of positive significance to the cultivation of national reading habits to a certain extent, whether it has a long-term effect still needs a certain mechanism to encourage and promote. The performance evaluation of library's reading promotion and promotion activities is not only conducive to the effective development of library's reading promotion, but also conducive to its sustainable development. The success of library's reading promotion work and activities needs to be evaluated and analyzed from many aspects and perspectives, such as the adequacy of the main body's preparation (financial resources, manpower and scope of activities), the obvious response of the audience (satisfaction, acceptance and participation), and whether the library's organizational promotion work and activities are in line with expectations. 


\section{B. Promoting the Effectiveness of Reading Promotion} Activities

The performance evaluation of library promotion activities can promote the effective development of reading promotion activities. Firstly, performance evaluation can help libraries effectively evaluate and summarize the effect of reading promotion activities from different angles and aspects evaluate the advantages and disadvantages of reading promotion activities in different stages, promote libraries to summarize reading promotion activities, and provide direction for libraries to carry out reading promotion activities. Sexual guidance enables them to develop their strengths and avoid weaknesses in future activities, and to give full play to the best organizational methods. Secondly, through the evaluation, it can effectively improve the library's reading promotion service ability. The object of performance evaluation includes organizers and participants. Organizers can summarize the advantages and disadvantages of the activities after the activities, and improve their reading promotion service ability continuously according to the evaluation results. Finally, through performance evaluation, participants can be guided. The purpose of evaluation is to guide readers to attach importance to reading, like reading, and make reading a part of daily life. Through the evaluation, the reference can feel the motivation and purpose of the evaluation; consciously get guidance, from being guided to being free to love reading.

\section{Promoting the Library to Build Full Business Service Institutions}

Although reading has become nationalized, some university libraries have established corresponding service departments, but the work of reading promotion is not the routine business of all libraries, some only hold reading activities on World Reading Day "4.23" or that month, and it has not become a daily work department. Through the performance evaluation of reading promotion and setting up a number of evaluation indicators, some libraries without reading promotion departments can be urged to improve and build corresponding daily reading service institutions, so that the library's reading promotion work becomes a daily business service.

\section{PRINCIPLES FOR ESTABLISHING EVALUATION OF READING PROMOTION WORK}

\section{A. Being People-oriented}

The service providers, organizers and participants involved in library reading promotion work are all related to "people", especially the participants. They are not only the object of library reading promotion service, but also the embodiment of the value of Library service. User satisfaction is an important criterion to measure library service work, and also the purpose and core of all library service work. Therefore, the people-oriented principle should be implemented in library evaluation work. On the one hand, it can not only improve the enthusiasm of the service providers and organizers, promote the quality of service and improve the library's reading promotion work; on the other hand, readers are the direct participants and beneficiaries of the library's reading promotion work. Reader's perception plays an important role in the whole reading promotion, and is the primary reference for evaluating the effect of the activities. From the reader's point of view, the evaluation of reading promotion also fully embodies the principle of "peopleoriented" in the library's reading promotion work.

\section{B. Being Operable}

The principle of operability includes three aspects: first, the structure and level of the evaluation system of reading promotion should be clear; second, the index content of the evaluation system of reading promotion should be reasonable and the data obtained should be accurate; third, the measurement criteria of the evaluation system of reading promotion should be quantified. The criteria are not complicated, the effectiveness should be emphasized and the operability should be highlighted. The evaluation of reading promotion should pay special attention to ensuring the scientific of the evaluation. In the design of indicators, people should pay attention to the representativeness of indicators and the integrity of the system, avoid duplication and omission between indicators, and also have logic between indicators. Indicators should be independent of each other, but also complementary to each other. At the same time, the quantitative indicators selected in the evaluation should be easy to operate, and the basis for qualitative analysis can be collected by interviews. It is easy to obtain those indices that are not quantitatively tested for fuzziness.

\section{Combining Qualitative and Quantitative Analysis}

Qualitative evaluation and quantitative evaluation are two basic methods of evaluation. The evaluation of reading promotion in University Libraries implements a variety of evaluation methods and measures. The construction of evaluation index system and standards can be achieved by defining the evaluation basis, determining evaluation grades and standards, determining index weights, and decomposing targets layer by layer. The evaluation information can be collected and analyzed by using literature, questionnaire and interview methods.

Through the combination of qualitative and quantitative methods, on the one hand, it can quantitatively analyze the quantitative relationship, characteristics and changes of various data indicators in the process of library reading promotion, revealing the completion of various indicators of reading promotion work, and on the other hand, it can deduce the development trend of reading promotion by using abundant evaluation experience, judgment and analysis ability through qualitative methods. The two methods complement each other in the evaluation process, and without any of them, it is not helpful to achieve an objective evaluation of reading promotion. If people leave qualitative to quantitative, they will lack analysis and judgment on the content that is difficult to quantify, and they will not solve complex problems. They will easily simplify the complex ideological problems and lead to the inaccuracy of the overall understanding. If people leave quantitative to qualitative, they will easily leave the understanding at a 
vague level of outline, and will not be clear and precise about the quantitative content, which will lead to subjective arbitrariness.

\section{STRATEGIES FOR ESTABLISHING EVALUATION OF READING PROMOTION WORK}

\section{A. Establishment of Evaluation System}

Any effective work needs to be guaranteed by the system. If people can establish an evaluation system focusing on the evaluation of reading promotion, it will play a role in promoting and guaranteeing the evaluation of reading promotion. The establishment of the evaluation system of reading promotion should be included in the key points of the development work of university libraries, which should include the attention of all levels from the school leaders to the library leaders, as well as the attention of every organizer, planner and implementer. The content of the evaluation system should cover resource allocation and behavioral motivation. The so-called resource allocation is to clearly read the human, material and financial resources to be invested in the promotion work, to clearly participate in the formulation of the system plan assessment personnel composition, normative requirements, division of labor and incentives, to clearly identify the resources and equipment needed to be invested and various financial expenditure guarantees. Secondly, because organizers and participants are motivated by the motivation of reading promotion evaluation, they will instinctively follow the objectives of the activities and carry out a series of beneficial activities in order to achieve their objectives. Therefore, the establishment of the evaluation system can mobilize the initiative of organizers and participants, so that the benefits obtained by the actors are consistent with their efforts.

\section{B. Establishment of Evaluation System}

According to the organizational situation and construction effect of university library's reading promotion work, the evaluation can be built into two dimensions: constructive evaluation index system and functional evaluation index system. According to the characteristics of university library's reading promotion work, the reading promotion work can be divided into organizational construction situation and service effect. Therefore, the reading promotion evaluation system can be divided into constructive evaluation and functional evaluation. Two firstlevel indicators are assessed. Constructive evaluation mainly investigates the work of reading promotion organizations in university libraries, and evaluates the "construction" and "non-construction" of the organizational work of professional institutions [Lu, 2015]. According to the content of reading promotion in university libraries, people can divide the constructive evaluation into three secondary indicators, which include the guarantee of organizational construction, the promotion of reading promotion and the inspection of reading promotion. Functional evaluation mainly inspects the specific effect of the university library's reading promotion work. It evaluates the "good or bad" of a specific work. It is mainly used to evaluate the reading activities held by the reading promotion. Functional evaluation system can be divided into two secondary index systems: internal effect index and external effect index. The internal index system examines the internal grasp of the effectiveness of reading promotion activities before, during and after the holding of reading promotion activities, and the external effect index is used to evaluate the effective impact on readers in the later stage of reading promotion activities.

\section{Assessment and Implementation}

According to the needs of evaluation and the different levels of university libraries, the evaluation subjects of different levels are determined. On this basis, the questionnaire and evaluation scale are designed according to the evaluation indicators. In the questionnaire and scale, not only the basic information of the respondents, but also the subjective consciousness of the respondents, such as their knowledge, willingness and ideas, are collected. Secondly, the information is consulted and the reports are listened to [Ding, 2018]. All-round information and data are collected by means of colloquium, field investigation and so on. Finally, some statistical software is used for data statistics, data collected are processed and evaluation reports are compiled. The evaluation results can also be used as an important basis for the annual assessment of the person in charge of reading promotion, the evaluation of the leading group first, and the selection and appointment of leading cadres.

\section{Evaluation Feedback}

The purpose of the evaluation of reading promotion is to make a reasonable evaluation of the results of reading promotion and reading promotion activities. It mainly considers the results of the activities, summarizes the results of the activities, shares the working experience, and then uses rewards and punishments to promote the work, and improves the development of reading promotion and reading promotion activities through effective ways such as testing and feedback. The feedback link of the evaluation of reading promotion is particularly important in the evaluation work. Through the feedback data, the implementation and effect of reading promotion activities can be qualitatively and quantitatively evaluated. Through the evaluation, the reading promotion activities can be consciously guided to the general objectives of school personnel training, scientific research and social services, and the service function of the library can be promoted. To achieve this goal, teachers and students should be guided to love reading, so as to play a leverage role by evaluating feedback. Secondly, by summarizing and reflecting on the information feedback of the evaluation results, including the overall evaluation results and the index results, the unsatisfactory data are comprehensively analyzed and the evaluation report is formed, the program is constantly adjusted, the best is created, and the evaluation of reading promotion is realized to promote the effective development of reading promotion, so as to make it develop towards standardization, institutionalization, standardization and scientificalization [Li, 2018]. 


\section{CONCLUSION}

Due to the emergence of various forms of media, readers' reading forms have changed in the new media environment. The work of reading promotion in university libraries has changed, and the channels and ways of reading promotion are also changing. The evaluation of reading promotion and reading promotion activities can effectively carry out reading promotion and improve the efficiency of reading promotion activities.

\section{REFERENCES}

[1] Yan Hongfeng. Construction of Reading Promotion Service Mechanism of University Library [J]. Journal of Mudanjiang Institute of Education, 2018 (05): 63-65.

[2] Lu Miaomiao, Direction is clear. Study on the Construction of Performance Evaluation Index System of Reading Promotion Activities in University Libraries [J]. Library Construction, 2015 (11): 34-37.

[3] Ding Yi. Practice of reporting and suggestions for future setting of the index part of "reading promotion" in the sixth evaluation of public libraries [J]. Library Research and Work, 2018 (04): 64-69.

[4] Li Ying. Establishment and research of evaluation mechanism for University reading promotion activities $[\mathrm{J}]$. Library work and research, 2018 (11): 124-128. 